\title{
Cardiovascular Risk in Adults and its Association with Health Services Utilization. ENSANUT 2018-2019
}

\author{
Sergio Flores Hernández ${ }^{1}$, Laura del Pilar Torres Arreola ${ }^{1}{ }^{*}$, Armando Nevarez Sida ${ }^{2}$, \\ Ofelia Poblano Verástegui ${ }^{1}$
}

${ }^{1}$ Research Center of Evaluation and Surveys, National Institute of Public Health, Cuernavaca, Mexico

${ }^{2}$ Research Unit in Epidemiologic and Health Services, Aging Area, Mexican Institute of Social Security, Mexico City, Mexico

Email: *laura.torres@insp.mx

How to cite this paper: Hernández, S.F., Arreola, L.P.T., Sida, A.N. and Verástegui, O.P. (2020) Cardiovascular Risk in Adults and its Association with Health Services Utilization. ENSANUT 2018-2019. World Journal of Cardiovascular Diseases, 10, 809-824. https://doi.org/10.4236/wjcd.2020.1012077

Received: September 12, 2020

Accepted: December 26, 2020

Published: December 29, 2020

Copyright $\odot 2020$ by author(s) and Scientific Research Publishing Inc. This work is licensed under the Creative Commons Attribution International License (CC BY 4.0).

http://creativecommons.org/licenses/by/4.0/

\begin{abstract}
Background The use of health services by the adult population is related to cardiovascular risk and its stratification. Cardiovascular risk (CVR) stratification should be a tool for the assessment of the patients and the appropriate control during the process of medical care and utilization of health services for the adults. Objective Evaluate the association between cardiovascular risk (CVR) in adults and the utilization of health services. Material and Methods A secondary analysis was performed of the data from the National Health and Nutrition Survey (ENSANUT) 2018-2019. The CVR classification (risk score) was obtained in 43,070 adults with a previous diagnosis (self-report) and 1,237 adults newly diagnosed. Independent, risk factors and the association between groups of CVR and utilization of preventive, outpatient and hospital services were analyzed. Results More than $85 \%$ of adults interviewed have some degree of CVR. Almost half of them have low CVR (48.2\%). Older adults with social security predominate in the group with high and very high CVR. Seventy-five percent of adults recently diagnosed have low CVR. In both, there is very little utilization of health services. For adults previously diagnosed CVR, the higher the CVR, the greater the likelihood of utilization of outpatient, preventive and hospital services, in contrast to adults without CVR independent of the marital status, sex, health institution and socioeconomic level. Conclusion The results give evidence of areas of opportunity for improvement in the quality of health services. The evaluation of CVR in primary care and promotion and prevention of CVR should be strengthened.
\end{abstract}

\section{Keywords}

Health Care Utilization, Health Care Accessibility, Cardiovascular Risk, Obesity, Chronic Conditions 


\section{Introduction}

Cardiovascular disease (CVD) is one of the main causes of mortality, and by 2030 will contribute to one quarter of deaths globally [1] [2]. In Mexico, CVD has been the main cause of death, with a total of 141,619 (20.1\%) in the period 2010-2017 [3]. A report of the global burden of the disease reveals that ischemic heart disease was responsible for almost 26 million years of daily activity (DALYS) lost as a result of premature death or disability [4].

It has been recognized that detection and control of cardiovascular risk (CVR) in adults due to hypertension, diabetes mellitus (DM), as well as other factors such as obesity, dyslipidemia, and smoking, among others, are important strategies whose evaluation accompanies decision making in the individual handling, treatment and prevention of CVD [5] [6] [7] [8]. Based on evidence, international organisms consider indispensable the evaluation of CVR, since it allows identification of the probability of developing a CVD within 10 years that would impact the burden of the disease and mortality [9]. A useful, appropriate stratification of CVR incorporates the unmodifiable cardiovascular risk factors (CVRF) such as age (relevant predictor) and the modifiable ones such as hypertension, which is strongly associated with CVD, diabetes or dyslipidemia; behavioral (smoking) or other biomarkers. In routine clinical practice, CVR is not usually stratified, in spite of the existence of applicable models (Framingham Risk Score (FRS) [10] [11], Systematic Coronary Risk Evaluation (SCORE) [12] and the World Health Organization International Society of Hypertension/WHO/ISH) [13].

CVD is the cause that most contributes to the utilization of health services and costs, especially in elderly populations [14].

There is no doubt that the factors that contribute to CVR affect people and the health system through the utilization of services, resources, and the costs [15]. There are some studies that approach health service utilization and indicate how factors intervene, under the Andersen model [16]: 1) those that predispose subjects to the utilization of services (age, sex, marital status); 2) those that allow or impede its utilization (socioeconomic level, access to health services); and 3) health needs (health-illness conditions) [17]. That is, the morbidity perceived by people with diagnosis (aware) or those without diagnosis (unaware or unknown) [18].

The utilization of services may be analyzed from various theoretical viewpoints (psychosocial, epidemiological, sociological or economic), and, in the majority, need is the explaining factor. Need, in the first instance as internal perception, is psychobiological, and later external, through surroundings and social connections of the person. Knowledge or unawareness of the disease is shared learning during socialization, experiences lived and the cultural framework of the "sick" person [19] [20] [21]. According to the Health Belief Model, the search for care from prevention, also called positive health, implies motivations for utilization of services, a minimum awareness of the disease, recognizing vulnerability and knowledge and acceptance of the effectiveness of an interven- 
tion [22].

There are few studies that have tried to explore how subjects with CVR utilize health services [23] [24]. The results of a recent national survey in European countries [23] concludes that adults with diagnosed CVD and low socioeconomic level need to utilize more health services, and that CVD plus comorbidities are associate with greater utilization of outpatient visits with a general physician, and that multimorbidity is a determinant in the utilization of health services [25]. In Mexico, the utilization of services by persons with CVR is little studied.

This work has as its objective establishing the association between CVR in adults with previous or recent diagnosis at the time of the survey, and the utilization of various health services (preventive, outpatient or hospitalization).

\section{Methods}

A secondary analysis was performed of the data from the National Health and Nutrition Survey (ENSANUT, National Health and Nutrition Survey) 2018-2019. The methodology of this complex probabilistic survey of homes, with sample design (multistage and stratified) and a representative sample of the national and state population is described elsewhere [26]. The survey contains information from 44,069 homes and 82,490 complete interviews. The response rate was $87 \%$.

Information used from the questionnaires included: Adult health (QS) of adults ( $n=43,070)$ and utilization of services by QS household-residents, as well as information from a sub-sample of adults who underwent measurements in situ (anthropometrics and blood pressure) on two occasions, as well as the results of laboratory analysis of biological samples of venous blood (glucose, total cholesterol, HDL cholesterol, LDL cholesterol and triglycerides) [27].

Six CVRF were identified and established as a compound indicator of CVR, giving a score to each of the CVRF plus the presence of morbidity with the following criteria (see Table 1 ): age (men $>55$ years $=1$, women $>65$ years $=1$ ), positive for smoking (currently smoking and over 100 cigarettes in lifetime $=1$ ), dyslipidemia (high cholesterol and triglycerides $=4$, high cholesterol or triglycerides $=3$ ), obesity (1), family history of early cardiovascular disease (1), plus having some other morbidity such as diabetes (1), chronic kidney disease (dialysis, hemodialysis or renal failure $=1$ ), cardiovascular (heart failure and infarction $=1$ ), and cerebrovascular (stroke, embolism =1) disease [28].

According to the information reported for the adults, they identified: 1) adults with previous diagnosis, who answered Yes to questions if a doctor had once told them they had some CVRF or a disease such as diabetes, chronic kidney disease, established cardiovascular condition or hypertension; and 2) recently-diagnosed adults (adults who on the health questionnaire reported none of the CRVF or morbidity), but who at the time of the interview, through the average of two measurements of weight, height and abdominal circumference were identified with obesity [body mass index $>30$ and abdominal circumference 
(men $\geq 102 \mathrm{~cm}$ and women $\geq 88 \mathrm{~cm}$ )], or who through laboratory results had, in $\mathrm{mg} / \mathrm{dL}$ (total cholesterol $>190$, LDL cholesterol $>115$, HDL cholesterol in men < 40 and in women $<46$, fasting glucose $>125$ ) or diabetes (plasma glucose $>126$ $\mathrm{mg} / \mathrm{dL}$ and/or glucosylated hemoglobin $>7 \%$ ) [29].

Table 1. Stratification of cardiovascular risk (cvr) according to risk factors and other parameters.

\begin{tabular}{ccc}
\hline RISK FACTORS $\left({ }^{*}\right)$ & CRITERIA & SCORE YES $=1 /$ NO $=0$ \\
\hline Age (years) ${ }^{*}$ & Man $\geq 55$ \\
Woman $\geq 65$ & Positive \\
Smoking* & Cholesterol $>190 \mathrm{mg} / \mathrm{dl}$ \\
Dyslipidemia ${ }^{*}$ & LDL cholesterol: $115 \mathrm{mg} / \mathrm{dl}$ \\
& HDL cholesterol: \\
& Men $<40 \mathrm{mg} / \mathrm{dl}$ \\
& Women $<46 \mathrm{mg} / \mathrm{dl}$ \\
Abnormal fasting glucose & Triglycerides $>150 \mathrm{mg} / \mathrm{dl}$ \\
Obesity & $102-125 \mathrm{mg} / \mathrm{dl}$ \\
Abdominal circumference & BMI $>30\left(\mathrm{~kg} / \mathrm{m}^{2} \mathrm{SC}\right)$ \\
& Men $102 \mathrm{~cm}$ \\
Family history of early CVD & Women $88 \mathrm{~cm}$ \\
& Men $<55 \mathrm{years}$ \\
& Women $<65$
\end{tabular}

${ }^{*}$ Sum (total) of risk factors (individual)

Identify the person with moderate to high CVR independently of the presence of risk factors $\left(^{*}\right)$ when present:

\section{DIABETES MELLITUS}

Plasma glucose and/or

Glucosylated hemoglobin and/or

Post-prandial plasma glucose
$126 \mathrm{mg} / \mathrm{dl}$ in 2 tests

$$
>7 \%
$$$$
>198 \mathrm{mg} / \mathrm{dl}
$$

Identify the person with HIGH CVR when present:

\section{ESTABLISHED KIDNEY OR VASCULAR DISEASE}
a. CKD with GFR
$<30 \mathrm{ml} / \mathrm{min}$
Proteinuria $>300 \mathrm{mg} / 24$ hours
b. Cardiovascular
Myocardial infarction,
chest angina and others
Infarction, cerebral
c. Cerebrovascular
hemmorhage,
transitory ischemic event

$\mathrm{CKD}=$ Chronic kidney disease $\mathrm{CVD}=$ Cardiovascular disease; $\mathrm{GFR}=$ Glomerular filtration rate; Notes: Calcification of CVR obtained adding individual factors and depending on associated comorbidities. Source: ESH-ESC, 2013. 
To identify CVR in categories: without CVR, low, moderate, high and very high CVR, scores were added up (1 point for each CVR), plus the presence of established morbidity, and these were related with the identification of hypertension (Table 2). Specifically, for adults with previous diagnosis, only the presence or lack of hypertension was considered, and for recently-diagnoses adults, groups were established according to the average of two measurements of systolic (SBP) and diastolic (DBP) blood pressure: normal blood pressure, normal-high (SBP 130 - 139 or DBP 85 - 89), grade 1 hypertension (SBP 140 - 159 or DBP 90 - 99), Grade 2 (SBP 160 - 179 or DBP 100 - 109), or Grade 3 (SBP $\geq$ 180 or $\mathrm{DBP} \geq 110$ [8] [28].

Information was considered for demographic variables (age, sex), academic level (last year and grade studied), marital status, most recent occupation, health institution (insured) and socioeconomic level defined with the same methodology as previous ENSANUT reports [29], as well as the utilization of preventive health services in the last 12 months (having gone to a preventive medicine module for the detection of diabetes (sugar test) or hypertension (taking of blood pressure) plus detection of overweight/obesity or dyslipidemias (abnormalities in cholesterol and triglycerides in blood); utilization of services in the last month for outpatients and in the last 12 months for hospitalization.

\section{Statistical analysis}

For statistics as proportions, means and 95\% confidence intervals (95\% CI), the design of the sample using complex survey was considered to obtain unbiased weighted estimations. To calculate variance, the strata with a single unit of sample were centered in global media. Sample sizes varied according to the variable under analysis. Groups of adults without CVR, low, moderate, and high-very high CVR were compared through Student $\mathrm{t}$ (Wald test) and 95\% CI.

Crude and adjusted odds ratios OR) and their 95\% CI were estimated for association of CVR (variable of interest) and health services utilization (dependent variable, yes $=1$, no $=0$ ) through logistic regression models separately for the utilization of each type of service utilization (preventive, outpatient and hospitalized) and in each model adjustment variables sex, marital status, health institution and socioeconomic level were considered.

All statistical analysis was performed with statistical program STATA version 16.0 (Stata, Stata Corp, College Station, TX).

\section{Results}

Of the 43,070 adults interviewed, $85.2 \%(n=37,070)$ showed some CVRF. Some $10.3 \%$ presented previously-diagnosed diabetes, $18.4 \%$ hypertension, and almost $4 \%$ of the total reported having established cardiovascular disease, chronic kidney disease or cerebrovascular disease. Of the 5651 adults without CVR by interview, a sample of 1237 had measurements in situ and laboratory results. Of these, $100 \%$ had at least some CVRF, $61.9 \%$ had three or more CVRF, $7.2 \%$ had diabetes and $23.4 \%$ hypertension (Table 3). All (100\%) had some degree of 
CVR.

In Table 4, of the adults interviewed, it is noted that of $14.1 \%$ of adults without CVR (did not report CVRF or previously-diagnosed morbidity), almost half were identified with low CVR and the rest with moderate, high or very high CVR.

Table 2. Gradation of cardiovascular risk according to blood pressure values and presence of risk factors.

\begin{tabular}{|c|c|c|c|c|}
\hline \multirow[t]{2}{*}{ Risk factors (CVRF), } & \multicolumn{4}{|c|}{ Blood pressure ( $\mathrm{mm} \mathrm{Hg}$ ) } \\
\hline & Normal high & Grade 1 HTA & Grade 2 HTA & Grade 3 HTA \\
\hline \multirow[t]{2}{*}{ Asymptomatic or disease } & SBP $130-139$ & SBP $140-159$ & SBP $160-179$ & $\mathrm{SBP} \geq 180$ \\
\hline & or DBP $85-89$ & or DBP 90 - 99 & or DBP $100-109$ & or $\mathrm{DBP} \geq 110$ \\
\hline Without another risk factor & & Low risk & Moderate risk & High risk \\
\hline $1-2$ risk factors & Low risk & Moderate risk & Moderate to high risk & High risk \\
\hline$\geq 3$ risk factors & Low to moderate risk & Moderate to high risk & High risk & High risk \\
\hline Stage 3 CKD or diabetes & Moderate to high risk & High risk & High risk & High to very high risk \\
\hline $\begin{array}{c}\text { Symptomatic CVD, } \\
\text { CKD stage } \geq 4 \text { or diabetes }\end{array}$ & Very high risk & Very high risk & Very high risk & Very high risk \\
\hline
\end{tabular}

$\mathrm{CKD}=$ Chronic kidney disease $\mathrm{CV}=$ cardiovascular; $\mathrm{CVD}=$ Cardiovascular disease; $\mathrm{SBP}=$ Systolic blood pressure; $\mathrm{DBP}=\mathrm{Diastolic}$ blood pressure; $\mathrm{HTA}=$ Hypertension. Source: ESH-ESC, 2013.

Table 3. Cardiovascular risk factors and morbidity in adults with previously-diagnosed and recently-diagnosed CVR, ENSANUT 2018-2019.

\begin{tabular}{|c|c|c|c|c|c|c|c|c|}
\hline & \multicolumn{4}{|c|}{$\begin{array}{l}\text { Adults with previous diagnosis } \\
\qquad \mathrm{n}=43,070\end{array}$} & \multicolumn{4}{|c|}{$\begin{array}{l}\text { Adults with recent diagnosis } \\
\text { (measured in situ and blood sample results) } \\
\qquad \mathrm{n}=1237\end{array}$} \\
\hline & $\mathrm{n}$ & $\%$ & \multicolumn{2}{|c|}{$95 \% \mathrm{CI}$} & $\mathrm{n}$ & $\%$ & \multicolumn{2}{|c|}{$95 \% \mathrm{CI}$} \\
\hline Without risk factor ${ }^{*}$ & 6000 & 14.9 & 14.3 & 15.4 & 0 & 0.0 & 0.0 & 0.1 \\
\hline $1-2$ risk factors ${ }^{\star}$ & 26,458 & 61.0 & 60.3 & 61.7 & 423 & 38.1 & 33.8 & 42.5 \\
\hline$\geq 3$ risk factors ${ }^{*}$ & 10,612 & 24.2 & 23.5 & 24.9 & 814 & 61.9 & 57.5 & 66.2 \\
\hline Diabetes & 4555 & 10.3 & 9.9 & 10.7 & 83 & 7.2 & 5.0 & 10.1 \\
\hline \multicolumn{9}{|c|}{ Chronic kidney disease or established cardiovascular disease } \\
\hline Chronic kidney disease $\|$ & 463 & 1.1 & 0.9 & 1.3 & 0 & 0.0 & 0.0 & 0.1 \\
\hline Cardiovascular disease \# & 1059 & 2.3 & 2.1 & 2.5 & 0 & 0.0 & 0.0 & 0.1 \\
\hline Cerebrovascular disease ${ }^{* *}$ & 210 & 0.5 & 0.4 & 0.6 & 0 & 0.0 & 0.0 & 0.1 \\
\hline Hypertension & 8253 & 18.4 & 17.8 & 19.0 & 293 & 23.4 & 19.6 & 27.7 \\
\hline
\end{tabular}

* CVR cardiovascular risk factors (sex, age, smoking, obesity, dyslipidemia, family history of early CVD); || Chronic kidney disease (dialysis, hemodialysis, kidney damage); \# CVD Cardiovascular disease (heart failure,coronary infarction); ${ }^{\star *}$ Cerebrovascular disease (stroke, embolism); ${ }^{\star}$ CVR cardiovascular risk factors: sex, age, obesity (BMI and abdominal circumference) and dislipidemia (concentration of cholesterol and triglycerides), abnormal fasting glucose, plus smoking and family history of early CVD denied; Source: National Health and Nutrition Survey 2018-2019. 
Table 4. Sociodemographic characteristics of adult population with and without CVR by previous diagnosis.

\begin{tabular}{|c|c|c|c|c|c|c|c|c|c|c|c|c|c|}
\hline \multirow[b]{4}{*}{ CVR categories } & \multirow{4}{*}{$\begin{array}{c}\mathrm{n} \\
43,070\end{array}$} & \multicolumn{3}{|c|}{$\begin{array}{c}\text { Without } \\
\text { cardiovascular risk }\end{array}$} & \multicolumn{9}{|c|}{ Cardiovascular risk $\mathrm{n}=37,419$} \\
\hline & & \multicolumn{3}{|c|}{$\mathrm{n}=5651$} & \multicolumn{3}{|c|}{$\begin{array}{c}\text { Low } \\
\mathrm{n}=20,890\end{array}$} & \multicolumn{3}{|c|}{$\begin{array}{c}\text { Moderate } \\
\mathrm{n}=8564\end{array}$} & \multicolumn{3}{|c|}{$\begin{array}{l}\text { High and very high } \\
\qquad n=7965\end{array}$} \\
\hline & & \multirow{2}{*}{$\begin{array}{c}\% \\
14.1\end{array}$} & \multicolumn{2}{|c|}{$(95 \% \mathrm{CI})$} & $\%$ & \multicolumn{2}{|c|}{$(95 \% \mathrm{CI})$} & $\%$ & \multicolumn{2}{|c|}{$(95 \% \mathrm{CI})$} & $\%$ & \multicolumn{2}{|c|}{$(95 \% \mathrm{CI})$} \\
\hline & & & 13.6 & 14.7 & 48.2 & 47.5 & 49.0 & 19.8 & 19.2 & 20.4 & 17.8 & 17.3 & 18.4 \\
\hline \multicolumn{14}{|l|}{ Sex } \\
\hline Women & 23,574 & 62.7 & 60.7 & 64.6 & 50.0 & 48.9 & 51.0 & 56.1 & 54.5 & 57.8 & 59.2 & 57.6 & 60.8 \\
\hline Men & 19,496 & 37.3 & 35.4 & 39.3 & 50.0 & 49.0 & 51.1 & 43.9 & 42.2 & 45.5 & 40.8 & 39.2 & 42.4 \\
\hline \multicolumn{14}{|l|}{ Age, mean } \\
\hline $20-44$ & 23,344 & 82.2 & 80.6 & 83.7 & 63.5 & 62.4 & 64.5 & 45.4 & 43.9 & 47.0 & 20.5 & 19.2 & 21.9 \\
\hline $45-64$ & 13,297 & 17.8 & 16.3 & 19.4 & 26.9 & 26.0 & 27.8 & 37.5 & 35.9 & 39.0 & 47.2 & 45.5 & 49.0 \\
\hline 65 or more & 6429 & NA & NA & NA & 9.6 & 9.0 & 10.3 & 17.1 & 15.9 & 18.4 & 32.2 & 30.6 & 33.8 \\
\hline \multicolumn{14}{|l|}{ Academic level } \\
\hline No studies & 2779 & 3.9 & 3.2 & 4.6 & 4.9 & 4.4 & 5.3 & 5.3 & 4.7 & 6.0 & 9.9 & 8.9 & 10.9 \\
\hline Unfinished primary & 5365 & 7.4 & 6.4 & 8.4 & 9.6 & 9.1 & 10.2 & 10.9 & 10.0 & 11.9 & 18.6 & 17.3 & 19.8 \\
\hline Finished primary & 7765 & 15.0 & 13.7 & 16.4 & 16.9 & 16.1 & 17.7 & 16.6 & 15.5 & 17.7 & 24.9 & 23.3 & 26.4 \\
\hline Junior high finished & 13,371 & 31.1 & 29.3 & 33.0 & 31.6 & 30.6 & 32.5 & 31.2 & 29.7 & 32.7 & 26.2 & 24.6 & 27.8 \\
\hline High school finished & 8069 & 27.3 & 25.4 & 29.2 & 22.2 & 21.3 & 23.1 & 19.2 & 17.9 & 20.6 & 11.0 & 10.0 & 12.0 \\
\hline University and post-graduate & 5721 & 15.4 & 14.0 & 17.0 & 14.8 & 14.1 & 15.6 & 16.8 & 15.6 & 18.0 & 9.6 & 8.5 & 10.8 \\
\hline \multicolumn{14}{|l|}{ Marital status } \\
\hline Married or common law & 26,642 & 60.6 & 58.6 & 62.5 & 63.3 & 62.3 & 64.3 & 65.0 & 63.4 & 66.5 & 67.0 & 65.5 & 68.5 \\
\hline Single & 7508 & 31.4 & 29.6 & 33.4 & 22.8 & 21.9 & 23.7 & 16.6 & 15.3 & 18.0 & 8.7 & 7.7 & 9.7 \\
\hline Widow or divorced & 8920 & 7.9 & 7.1 & 8.9 & 13.9 & 13.3 & 14.7 & 18.4 & 17.3 & 19.6 & 24.3 & 23.0 & 25.7 \\
\hline \multicolumn{14}{|l|}{ Occupation } \\
\hline Employer & 637 & 0.6 & 0.4 & 1.0 & 1.3 & 1.1 & 1.5 & 1.2 & 1.0 & 1.5 & 1.3 & 1.0 & 1.6 \\
\hline Formal worker & 18,812 & 46.3 & 44.2 & 48.4 & 48.3 & 47.2 & 49.3 & 43.1 & 41.6 & 44.7 & 28.2 & 26.6 & 29.7 \\
\hline Informal worker & 8758 & 17.1 & 15.6 & 18.7 & 19.8 & 19.0 & 20.7 & 19.4 & 18.2 & 20.6 & 20.4 & 19.1 & 21.7 \\
\hline Retired/pensioned & 1843 & 0.4 & 0.2 & 0.7 & 2.5 & 2.2 & 2.8 & 6.3 & 5.5 & 7.2 & 10.3 & 9.3 & 11.5 \\
\hline Student & 631 & 5.3 & 4.4 & 6.5 & 2.5 & 2.2 & 2.9 & 1.3 & 0.9 & 1.9 & 0.2 & 0.1 & 0.4 \\
\hline Does not work & 12,389 & 30.2 & 28.5 & 32.1 & 25.6 & 24.7 & 26.5 & 28.7 & 27.2 & 30.3 & 39.6 & 38.0 & 41.3 \\
\hline \multicolumn{14}{|l|}{ Health institution } \\
\hline Without social security & 6961 & 22.8 & 20.9 & 24.7 & 20.8 & 20.0 & 21.7 & 16.5 & 15.1 & 17.9 & 11.4 & 10.3 & 12.5 \\
\hline $\begin{array}{l}\text { Social security } \\
\text { (IMSS or ISSSTE) }\end{array}$ & 19,634 & 37.2 & 35.2 & 39.2 & 42.6 & 41.6 & 43.7 & 52.1 & 50.4 & 53.7 & 56.1 & 54.4 & 57.8 \\
\hline Secretaria de salud & 15,803 & 38.5 & 36.5 & 40.5 & 34.5 & 33.5 & 35.6 & 29.4 & 28.0 & 30.9 & 30.6 & 29.1 & 32.1 \\
\hline $\begin{array}{l}\text { Other health service } \\
\text { (private/other) }\end{array}$ & 672 & 1.6 & 1.1 & 2.2 & 2.0 & 1.7 & 2.3 & 2.0 & 1.7 & 2.5 & 2.0 & 1.6 & 2.5 \\
\hline
\end{tabular}




\section{Continued}

\begin{tabular}{|c|c|c|c|c|c|c|c|c|c|c|c|c|c|}
\hline \multicolumn{14}{|c|}{ Use of preventive services in the last 12 months } \\
\hline No & 39,142 & 95.7 & 95.0 & 96.4 & 91.3 & 90.7 & 91.9 & 88.3 & 87.3 & 89.2 & 92.0 & 91.0 & 92.8 \\
\hline Yes & 3928 & 4.3 & 3.6 & 5.0 & 8.7 & 8.1 & 9.3 & 11.7 & 10.8 & 12.7 & 8.0 & 7.2 & 9.0 \\
\hline \multicolumn{14}{|c|}{ Use of outpatient services in the last month } \\
\hline No & 36,544 & 92.9 & 91.9 & 93.8 & 90.2 & 89.6 & 90.8 & 83.1 & 81.9 & 84.2 & 72.6 & 71.0 & 74.1 \\
\hline Yes & 6526 & 7.1 & 6.2 & 8.1 & 9.8 & 9.2 & 10.4 & 16.9 & 15.8 & 18.1 & 27.4 & 25.9 & 29.0 \\
\hline \multicolumn{14}{|c|}{ Use of hospital care services in the last 12 months } \\
\hline No & 40,373 & 95.2 & 94.3 & 95.9 & 95.7 & 95.3 & 96.0 & 94.5 & 93.9 & 95.1 & 89.9 & 88.8 & 90.8 \\
\hline Yes & 2697 & 4.8 & 4.1 & 5.7 & 4.3 & 4.0 & 4.7 & 5.5 & 4.9 & 6.1 & 10.1 & 9.2 & 11.2 \\
\hline
\end{tabular}

Source: National Health and Nutrition Survey 2018-2019.

Upon comparing groups of CVR, differences were observed by sex, as men predominated in groups with CVR in contrast to women in the groups of adults without CVR. With regards to occupation, almost half of those with formal work were in groups without CVR or with low or moderate CVR, while those who did not work predominated in the high and very high CVR group. Regarding the institution to which they turned for care, it was observed that the greatest proportion of adults with moderate and high CVR use the services of the Mexican Institute of Social Security (IMSS, for workers and their dependents) versus adults without CVR or with low CVR using the services of the Ministry of Health $(\mathrm{MoH})$. To the question on the utilization of preventive services in the last 12 months, data showed that more than $90 \%$ of adults did not use them, and only close to $11.7 \%$ of the adults with moderate CVR noted having used these services. In the last month, only $7.1 \%$ of the adults without CVR reported having use outpatient services, while $27.4 \%$ of the adults with high and very high CVR used them. In the last 12 months, less than $5 \%$ of adults without CVR, in contrast to $10 \%$ of adults with high and very high CVR used hospital services.

In adults with recently-diagnosed CVR, almost $80 \%$ had low CVR, and the rest had moderate and high CVR, with a higher proportion of women in the group of adults with low CVR and almost 50\% of the men in the group with moderate CVR. There were differences in age; in the group of adults without CVR, almost $85 \%$ were between 20 and 44 years, and 50\% of adults between 45 and 64 years were in the high and very high CVR group. Higher academic level (finished high school) was observed in the group without CVR, unlike the group with CVR, where junior high school predominated. In all groups with CVR, married or common law marital status predominated. Formal work predominated in groups with low CVR and not working in the group with high and very high CVR. In the last 12 months, more than $90 \%$ of the adults did not use preventive services, and only $6.0 \%$ of the adults with high and very high CVR used them. In the last month, while $10.9 \%$ of the adults without CVR used outpatient services, only around $5 \%$ of the adults with moderate, high or very high CVR used them. In the last 12 months, $6 \%$ of adults without CVR and a lower propor- 
tion (between $2 \%$ and $4 \%$ ) of adults with moderate, high or very high CVR used hospital services, Table 5.

Table 6 shows a statistically significant association between previously-diagnosed CVR and utilization of preventive, outpatient and hospital services. Specifically, independent of sex, marital status, health institution of care and socioeconomic level, the possibilities of preventive services were $106 \%$ more in adults with low CVR, 163\% for moderate CVR and 69\% more for high and very high CVR, in contrast with the group of adults without CVR. The utilization of outpatient services was higher the greater the possibility of major CVR (OR 1.47 (low RCV), 2.6 (Moderate CVR) and 4.8 (High and very high CVR), respectively) compared with the group without CVR.

Table 5. Sociodemographic characteristics of adults with recently-diagnosed CVR, ENSANUT 2018-2019.

\begin{tabular}{|c|c|c|c|c|c|c|c|c|c|c|}
\hline \multirow[b]{4}{*}{ Categories of CVR } & \multirow{4}{*}{$\begin{array}{c}\mathrm{n} \\
1237\end{array}$} & \multicolumn{9}{|c|}{ Cardiovascular risk $\mathrm{n}=1237$} \\
\hline & & \multicolumn{3}{|c|}{ Low $\mathrm{n}=937$} & \multicolumn{3}{|c|}{ Moderate $n=167$} & \multicolumn{3}{|c|}{ High and very high $n=133$} \\
\hline & & \multirow{2}{*}{$\begin{array}{c}\% \\
75.5\end{array}$} & \multicolumn{2}{|c|}{$95 \%$ CI } & \multirow{2}{*}{$\begin{array}{c}\% \\
14.3\end{array}$} & \multicolumn{2}{|c|}{$95 \%$ CI } & \multirow{2}{*}{$\begin{array}{c}\% \\
10.2\end{array}$} & \multicolumn{2}{|c|}{$95 \%$ CI } \\
\hline & & & 71.0 & 79.4 & & 11.3 & 17.9 & & 7.9 & 13.0 \\
\hline \multicolumn{11}{|l|}{ Sex } \\
\hline Women & 819 & 69.8 & 65.1 & 74.1 & 53.2 & 40.5 & 65.4 & 61.0 & 47.9 & 72.6 \\
\hline Men & 418 & 30.2 & 25.9 & 34.9 & 46.8 & 34.6 & 59.5 & 39.0 & 27.4 & 52.1 \\
\hline \multicolumn{11}{|l|}{ Age, mean } \\
\hline $20-44$ & 974 & 84.6 & 80.4 & 88.0 & 75.8 & 67.3 & 82.6 & 49.5 & 36.5 & 62.7 \\
\hline $45-64$ & 263 & 15.4 & 12.0 & 19.6 & 24.2 & 17.4 & 32.7 & 50.5 & 37.3 & 63.5 \\
\hline 65 or more & 0 & 0.0 & NA & NA & 0.0 & NA & NA & 0.0 & NA & NA \\
\hline \multicolumn{11}{|l|}{ Academic level } \\
\hline No studies & 64 & 3.6 & 2.3 & 5.5 & 4.4 & 2.4 & 8.2 & 12.4 & 5.5 & 25.7 \\
\hline Unfinished primary & 138 & 7.3 & 5.4 & 9.9 & 15.5 & 9.6 & 24.0 & 14.4 & 8.0 & 24.5 \\
\hline Finished primary & 234 & 15.5 & 12.5 & 19.0 & 16.9 & 10.6 & 25.7 & 24.3 & 14.4 & 37.9 \\
\hline Junior high finished & 411 & 28.1 & 23.9 & 32.7 & 35.4 & 24.6 & 48.0 & 23.5 & 15.2 & 34.6 \\
\hline High school finished & 284 & 36.1 & 30.8 & 41.7 & 18.9 & 10.8 & 30.9 & 22.0 & 12.6 & 35.5 \\
\hline University and post-graduate & 106 & 9.5 & 7.2 & 12.6 & 8.9 & 4.1 & 18.0 & 3.3 & 1.4 & 7.7 \\
\hline \multicolumn{11}{|l|}{ Marital status } \\
\hline Married or common law & 801 & 56.9 & 51.5 & 62.2 & 61.1 & 49.0 & 72.0 & 74.7 & 62.0 & 84.2 \\
\hline Single & 295 & 33.7 & 28.5 & 39.4 & 31.9 & 21.3 & 44.9 & 18.1 & 9.7 & 31.2 \\
\hline Widow or divorced & 141 & 9.3 & 7.0 & 12.3 & 6.9 & 3.3 & 14.0 & 7.2 & 3.6 & 14.1 \\
\hline \multicolumn{11}{|l|}{ Occupation } \\
\hline Employer & 5 & 0.3 & 0.1 & 0.9 & 0.9 & 0.1 & 5.9 & 0.0 & NA & NA \\
\hline Formal worker & 511 & 43.4 & 38.3 & 48.5 & 33.7 & 22.3 & 47.3 & 33.1 & 23.0 & 44.9 \\
\hline Informal worker & 265 & 17.2 & 14.1 & 20.8 & 29.4 & 18.6 & 43.3 & 27.0 & 17.4 & 39.5 \\
\hline Retired/pensioned & 2 & 0.1 & 0.0 & 0.3 & 0.0 & NA & NA & 0.0 & NA & NA \\
\hline Student & 41 & 7.5 & 4.8 & 11.5 & 1.9 & 0.5 & 7.1 & 4.2 & 0.6 & 24.0 \\
\hline Does not work & 413 & 31.7 & 27.5 & 36.1 & 34.2 & 24.2 & 45.8 & 35.7 & 25.4 & 47.6 \\
\hline
\end{tabular}




\section{Continued}

\begin{tabular}{|c|c|c|c|c|c|c|c|c|c|c|}
\hline \multicolumn{11}{|l|}{ Health institution } \\
\hline Without social security & 206 & 20.9 & 16.7 & 25.7 & 27.1 & 16.6 & 41.0 & 13.6 & 7.8 & 22.6 \\
\hline Social security (IMSS or ISSSTE) & 396 & 37.9 & 32.9 & 43.1 & 33.3 & 23.0 & 45.4 & 27.4 & 17.6 & 40.1 \\
\hline Secretaria de salud & 627 & 40.9 & 35.8 & 46.2 & 39.6 & 30.4 & 49.7 & 54.9 & 41.6 & 67.5 \\
\hline Other health service (private/other) & 8 & 0.4 & 0.2 & 1.0 & 0.0 & NA & NA & 4.2 & 0.6 & 24.0 \\
\hline \multicolumn{11}{|c|}{ Use of preventive services in the last 12 months } \\
\hline No & 1192 & 97.0 & 93.9 & 98.6 & 95.0 & 88.6 & 97.9 & 94.0 & 81.6 & 98.2 \\
\hline Yes & 45 & 3.0 & 1.4 & 6.1 & 5.0 & 2.1 & 11.4 & 6.0 & 1.8 & 18.4 \\
\hline \multicolumn{11}{|c|}{ Use of outpatient services in the last month } \\
\hline No & 1128 & 89.1 & 84.8 & 92.2 & 94.9 & 89.5 & 97.6 & 94.4 & 88.2 & 97.4 \\
\hline Yes & 109 & 10.9 & 7.8 & 15.2 & 5.1 & 2.4 & 10.5 & 5.6 & 2.6 & 11.8 \\
\hline \multicolumn{11}{|c|}{ Use of hospital care services in the last 12 months } \\
\hline No & 1180 & 93.8 & 91.0 & 95.7 & 97.7 & 93.5 & 99.2 & 96.4 & 91.4 & 98.5 \\
\hline Yes & 57 & 6.2 & 4.3 & 9.0 & 2.3 & 0.8 & 6.5 & 3.6 & 1.5 & 8.6 \\
\hline
\end{tabular}

Source: National Health and Nutrition Survey 2018-2019.

Table 6. Use of services and cardiovascular risk in adults, ENSANUT 2018-2019.

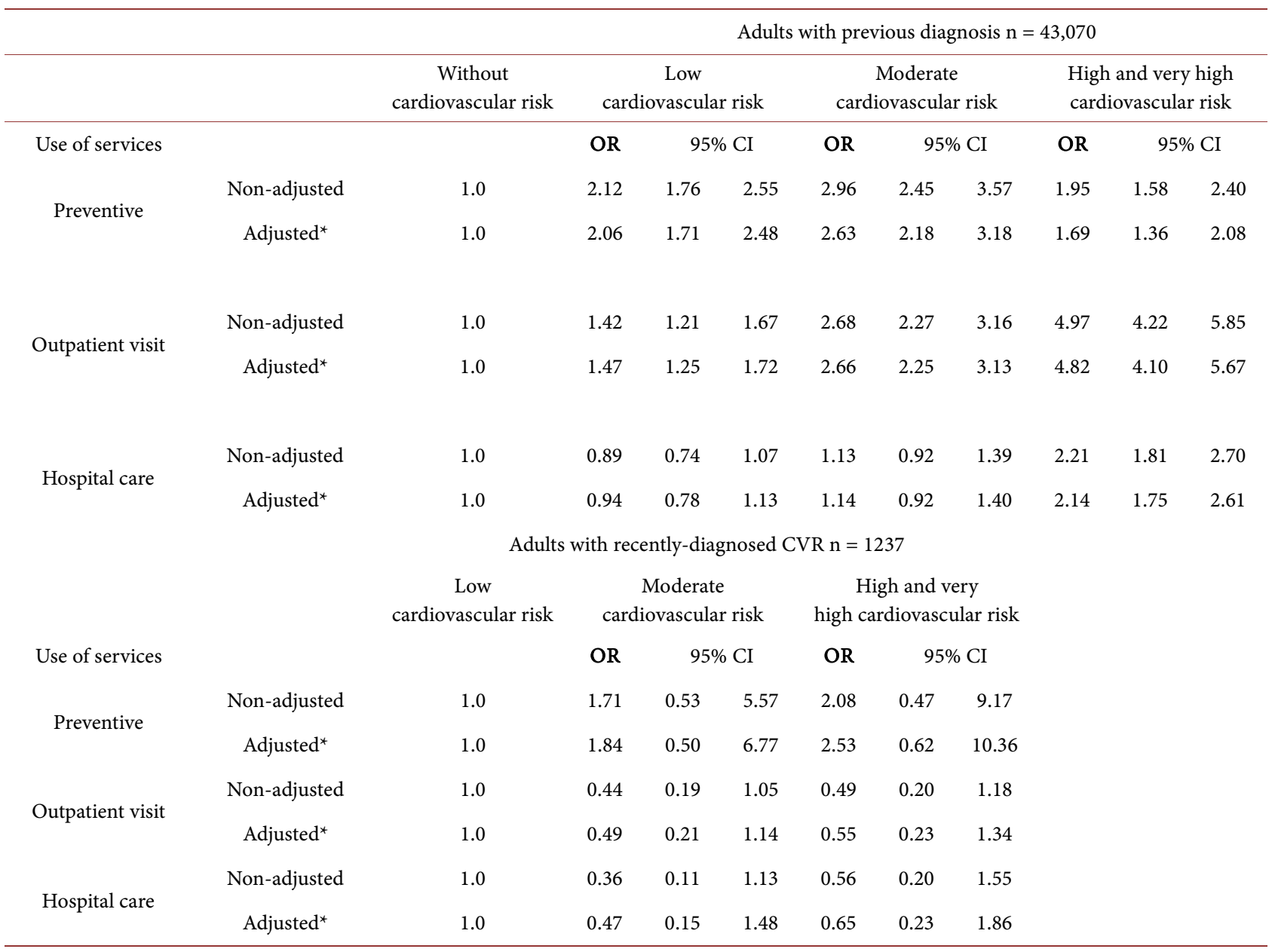

* Logistic regression, model adjusted for marital status, sex, health institution, socioeconomic level. 
The utilization of hospital services was statistically significant, with higher possibility in the group of adults with high and very high CVR (OR 2.14, 95\% CI 1.75 - 2.61) compared with adults without CVR.

In a similar analysis of adults with recently-diagnosed CVR, there was no statistically significant association between the degree of CVR and the utilization of preventive, outpatient or hospital services.

\section{Discussion}

This study analyzed CVR with information derived from a population survey of previously-diagnosed adults and those identified with CVR at the time of the survey (recently-diagnosed), and their utilization of health services.

An important first finding was that almost 2 of every 10 adults surveyed did not mention having or suffering any of the modifiable CVRF. However, when considering measurements in situ and the results of determinations in blood at the time of the interview, 1 in every 3 had come cardiovascular risk factor, 7\% had levels of hyperglycemia or glycosylated hemoglobin for a diagnosis of diabetes, and 1 in 5 had systemic hypertension. These CVR data include non-modifiable and modifiable risk factors, and may reveal two aspects: little knowledge of the meaning of CVR and low quality of care offered by health services in educational actions and the promotion of health. That is, possibly due to inadequate communication between health personnel and the patient, psychosocial and community reference context about the potential damage to health of modifiable and non-modifiable CVRF connected with certain grade of CVR. This finding and its possible consequences are consistent with what occurs only in diabetes, according to the International Federation of Diabetes [30], where in Mexico, it is estimated that 1 in 3 adults without diagnosis suffer it (prevalence of $38.6 \%, 4.9$ million people aged 20 years or more).

Adults who reported a previous diagnosis of some of the criteria of CVR were mainly men, with higher risk in the elderly. In particular, this group showed a negative impact for the possibility that outpatient services offer timely treatment due to the higher possibility or presenting difficult-to-treat complications (chronic kidney disease, cardiovascular damage or fatal cerebrovascular event). Some of these older adults are those that utilize hospital care only for vigilance and maintenance of established morbidity. However, many others do not go to health services, where they would have care with preventive measures for the low CVR they currently have. This means that there are areas of opportunity for effective primary care, focused on improving the care programs for patients with early diagnosis of CVR, with interventions to modify lifestyle and change to healthy behaviors as the most important step for both the health system and the patient, without forgetting that to achieve a change the perceived need should be taken into account, and the knowledge of adults concerning the importance of turning to health services for timely detection and care should be reinforced [31]. 
The relevance of the utilization of health services and cardiovascular risk is undoubted. The main hypothesis of this analysis was that higher CVR reported in adults would translate into greater use of health services, based on models that indicate that health care attitudes depend on awareness, context and acceptance of a disease model that indicates potential damage to health. However, it was important to independently analyze then kind of service used, and whether adults had previously-diagnosed or recently-diagnosed CVR. The low usage of preventive services in adults with high and very high CVR places in evidence that health services require a preventive more than curative focus in order to be able to achieve results in health, through the early identification of modifiable risk factors. To reduce the early complications and increase the adequate use of resources, programs for the care of chronic diseases should include the management of risks [32] [33], where the service provider and the patient share responsibility for the vigilance and control of risk factors, which might reduce the probability of complications and hospitalization.

People effectively identified and appropriately stratified according to CVR in advanced stage use outpatient and hospital services more, similar to that reported by others [22], and it is suggested that socioeconomic level plays a role as facilitator, and, in consequence, the overutilization that may affect the ability of the health system to respond to the needs of the population [34].

\section{Limitations}

This work has as its strength the proposal to evaluate CVR in adults with previous diagnosis or without, as a practical, feasible evaluation that could be useful for health professionals. However, it has some limitations in the scope of measuring CVR, since it does not include health behaviors, but independently considers the self-reported presence of CVR in adults with previous diagnosis and biochemical values in blood at the time of the survey for adults with recently-diagnosed CVR. The decision is based on the fact that in adults with previous diagnosis of CVR, measurements in situ and blood determinations at the time of the interview result being the best medical handling received, at least in the last year. Another limitation is the possible bias of the evaluation of CVR by self-report, since perhaps only adults who have accepted their vulnerability to cardiovascular disease, for its being consistent with their social-family context, answered the affirmative when a physician told them they had or suffered some of the CVRF or morbidity, and, on the other hand, the health questionnaire did not have questions that would allow establishing the severity of damage to the target organ or established morbidity for the classification of moderate to high and very high CVR, which might lead to an over-estimation of CVR in these cases.

\section{Conclusions}

Analysis of the association between CVR and health service utilization indicates 
the common practice and the perception the population has regarding the risk of the disease, given the presence of certain modifiable and non-modifiable factors that have been emphatically mentioned in the various strategies of primary prevention, implemented to reduce both CVR and cardiovascular disease [35].

The prevention of cardiovascular disease focused on modification of CVRF and the evaluation of CVR as strategies to implement with timely interventions directed towards changes in lifestyle, in addition to specific pharmacological handling are a current challenge that still exists in our context. Some $44.4 \%$ of the adults with previous diagnosis require actions focused on modifying lifestyle, and approximately $30 \%$ of the population requires the use of specific medications to control the disease, in addition to non-pharmacological strategies that have been shown to be effective.

In summary, from the perspective of the health services, there are various areas of opportunity, such as training health personnel to care for each adult and establish his CVR, which would determine the actions to implement and avoid the appearance of modifiable risk factors such as obesity, diabetes and hypertension through preventive measures such as physical activity and healthy diet, in addition to an appropriate pharmacological treatment according to age and the presence or absence of complications.

\section{Authors' Contributions}

LT, SF designed the study. AN was involved in the analysis. LT, SF, were involved in drafting the manuscript. LT, SF, AN and OP reviewed the manuscript. All authors approved this final manuscript.

\section{Funding}

No external funding was received for this study.

\section{Conflicts of Interest}

The authors declare no conflicts of interest regarding the publication of this paper.

\section{References}

[1] World Health Organization (2013) A Global Brief of Hypertension: Silent Killer, Global Public Health Crisis. World Health Organization, Geneva.

[2] (2015) Global, Regional, and National Age-Sex Specific All-Cause and Cause-Specific Mortality for 240 Causes of Death, 1990-2013: A Systematic Analysis for the Global Burden of Disease Study 2013. The Lancet, 385, 117-171. https://doi.org/10.1016/S0140-6736(14)61682-2

[3] Panorama Epidemiológico (2018) Enfermedades no Transmisibles. Oservatorio de Enfermedades No Transmisibles. Secretaría de Salud. Subsecretaría de Promoción y Prevención de la Salud. Dirección General de Epidemiología.

[4] Institute for Health Metrics and Evaluation (2013) The Global Burden of Disease: Generating Evidence, Guiding Policy. IHME, Seattle. 
[5] Hobbs, F.D.R. (2004) Cardiovascular Disease: Different Strategies for Primary and Secondary Prevention? Heart, 90, 1217-1223. https://doi.org/10.1136/hrt.2003.027680

[6] Hsu, S., Van-Khue, T., Ashen, D., Martin, S.S., Gluckman, T., Kohli, P., Sisson, S.D., Blumenthal, R.S. and Blaha, M. (2013) A Clinician's Guide to the ABCs of Cardiovascular Disease Prevention: The Johns Hopkins Ciccarone Center for the Prevention of Heart Disease and American College of Cardiology Cardiosource Approach to the Million Hearts Initiative. Clinical Cardiology, 36, 383-393.

https://doi.org/10.1002/clc.22137

[7] Gupta, R. and Wood, D.A. (2019) Primary Prevention of Ischaemic Heart Disease: Populations, Individual, and Health Professionals. The Lancet, 394, 685-696. https://doi.org/10.1016/S0140-6736(19)31893-8

[8] Guía de Práctica Clínica. Detección y Estratificación de Factores de Riesgo Cardiovascular. Evidencias y Recomendaciones. México, Secretaría de Salud. 2010. http://www.cenetec.salud.gob.mx/descargas/gpc/CatalogoMaestro/421IMSS_421_11 _Factores_riesgo_cardiovascular/IMSS_421_11_RIESGOCARDIOVASCULAR.pdf

[9] Collins Dylan, R.J., Tompson Alice, C., Onakpoya, I.J., Roberts, N., Ward, A.M. and Heneghan, C.J. (2017) Global Cardiovascular Risk Assessment in the Primary Prevention of Cardiovascular Disease in Adults: Systematic Review of Systematic Reviews. BMJ Open, 7, e013650. https://doi.org/10.1136/bmjopen-2016-013650

[10] Conroy, R.M., et al. (2003) Estimation of Ten-Year Risk of Fatal Cardiovascular Disease in Europe: The SCORE Project. European Heart Journal, 24, 987-1003. https://doi.org/10.1016/S0195-668X(03)00114-3

[11] Tsao, C.W. and Vasan, R.S. (2005) The Framingham Heart Study: Past, Present and Future. International Journal of Epidemiology, 44, 1763-1766. https://doi.org/10.1093/ije/dyv336

[12] Piepoli, M.F., Hoes, A.W., Agewall, S., Albus, C., Brotons, C., Catapano, A.L., Cooney, M.-T., Corrà, U., Cosyns, B., Deaton, C., Hall, I.G.M.S., Hobbs, F.D.R., Løchen, M.-L., Löllgen, H., Marques-Vidal, P., Perk, J., Prescott, E., Redon, J., Richter, D.J., Sattar, N., Smulders, Y., Tiberi, M., van der Worp, H.B., van Dis, I., Verschuren, W.M.M. and Binno, S., ESC Scientific Document Group. (2016) 2016 European Guidelines on Cardiovascular Disease Prevention in Clinical Practice: The Sixth Joint Task Force of the European Society of Cardiology and Other Societies on Cardiovascular Disease Prevention in Clinical Practice (Constituted by Representatives of 10 Societies and by Invited Experts) Developed with the Special Contribution of the European Association for Cardiovascular Prevention \& Rehabilitation (EACPR). European Heart Journal, 37, 2315-2381. https://doi.org/10.1093/eurheartj/ehw106

[13] Dugee, O., Sophal, O. and Brian, S.B. (2013) Assessment of Total Cardiovascular Risk Using WHO/ISH Risk Prediction Charts in Three Low and Middle-Income Countries in Asia. BMC Public Health, 13, 539.

https://doi.org/10.1186/1471-2458-13-539

[14] Azhar, G. and Wei, J.Y. (2015) The Demographics of Aging and Its Impact on the Cardiovascular Health. Current Cardiovascular Risk Reports, 9, 13.

https://doi.org/10.1007/s12170-015-0441-x

[15] Mavaddat, N. and Mant, J. (2010) Primary Care Research and Clinical Practice: Cardiovascular Disease. Postgraduate Medical Journal, 86, 696-703.

https://doi.org/10.1136/pgmj.2009.094771

[16] Andersen, R.M. (2008) National Health Surveys and the Behavioral Model of Health Services Use. Medical Care, 46, 647-653. https://www.jstor.org/stable/40221718 
https://doi.org/10.1097/MLR.0b013e31817a835d

[17] Kim, H.-K. and Lee, M. (2016) Factors Associated with Health Services Utilization between the Years 2010 and 2012 in Korea: Using Andersen's Behavioral Model. Osong Public Health and Research Perspectives, 7, 18-25.

https://doi.org/10.1016/j.phrp.2015.11.007

[18] Wekesah, F.M., Kyobutungi, C., Grobbee, D.E., et al. (2019) Understanding of and Perceptions towards Cardiovascular Diseases and Their Risk Factors: A Qualitative Study among Residents of Urban Informal Settings in Nairobi. BMJ Open, 9, e026852. https://doi.org/10.1136/bmjopen-2018-026852

[19] Arredondo, A. (2010) Factores asociados a la búsqueda y uso de servicios de salud: Del modelo psicosocial al socioeconómico. Salud Mental, 33, 397-408.

[20] Rosenstock, J.M. (1986) Why People Use Health Services (Part Two). Milbank Memorial Fund Quarterly, 44, 385-393. https://doi.org/10.2307/3348967

[21] Mechanic, D. (1995) Sociological Dimensions of Illness Behavior. Social Science \& Medicine, 41, 1207-1216. https://doi.org/10.1016/0277-9536(95)00025-3

[22] Rosenstock, I.M. (1974) The Health Belief Model and Preventive Health Behavior. Health Education Monographs, 2, 354-386. https://doi.org/10.1177/109019817400200405

[23] Karyn, M. (2019) Comorbidity and Healthcare Use for Individuals with CVD in the Ireland: A Cross-Sectional, Population-Based Study. BMJ Open, 9, e025305.

https://doi.org/10.1136/bmjopen-2018-025305

[24] de Moraes, S.A., Lopesi, D.A. and de Freitas, I.C.M. (2014) Sex-Specific Differences in Prevalence and in the Factors Associated to the Search for Health Services in a Population Based Epidemiological Study. Revista Brasileira de Epidemiologia, 17, 323-340. https://doi.org/10.1590/1809-4503201400020004ENG

[25] Palladino, R., Tayu, L.J., Ashworth, M., Triassi, M. and Millett, C. (2016) Associations between Multimorbidity, Healthcare Utilization and Heath Status: Evidence from 16 European Countries. Age and Ageing, 45, 431-435.

https://doi.org/10.1093/ageing/afw044

[26] Romero-Martínez, M., Shamah-Levy, T., Vielma-Orozco, E., Heredia-Hernández, O., Mojica-Cuevas, J., Cuevas-Nasu, L., et al. (2019) Encuesta Nacional de Salud y Nutrición 2018-19: Metodología y perspectivas. Salud Pública de México, 61, 917-923. https://doi.org/10.21149/11095

[27] INEGI. INSP Encuesta Nacional de Salud y Nutrición 2018 ENSANUT Diseño Conceptual 2019.

https://www.inegi.org.mx/contenidos/programas/ensanut/2018/doc/ensanut_2018_ diseno_conceptual.pdf

[28] Authors/Task Force Members, et al. (2013) ESH/ESC Guidelines for the Management of Arterial Hypertension: The Task Force for the Management of Arterial Hypertension of the European Society of Hypertension (ESH) and of the European Society of Cardiology (ESC). European Heart Journal, 34, 2159-2219.

[29] Gutiérrez, J.P. (2013) Clasificación socioeconómica de los hogares en la ENSANUT 2012. Salud Pública de México, 55, S341-S346. https://doi.org/10.21149/spm.v55s2.5133

[30] Federación Internacional de Diabetes (2019) Atlas de la Diabetes de la FID. 9th edición, Federación Internacional de Diabetes, Bruselas. https://www.diabetesatlas.org

[31] Ni, Y., Liu, S., Li, J., Li, S. and Dong, T. (2020) Patient-Perceived Service Needs and Health Care Utilization in People with Type 2 Diabetes. A Multicenter Cross-Sectional 
Study. Medicine, 99, e20322. https://doi.org/10.1097/MD.0000000000020322

[32] Organización Panamericana de la Salud (2007) Estrategia regional y plan para un enfoque integrado sobre la prevención y el control de las Enfermedades Crónicas. Ops, Washington DC.

[33] Gaziano, T.A., Reddy, K.S., Paccaud, F., Horton, S. and Chaturvedi, V. (2006) Cardiovascular Disease. In: Jamison, D.T., et al., Eds., Disease Control Priorities in Developing Countries, 2th Edition, Chapter 33, Oxford University Press, Oxford, 1-63.

[34] Chicafu, H. and Chimbari, M.J. (2019) Cardiovascular Disease Healthcare Utilization in Sub-Saharan Africa: A Scoping Review. International Journal of Environmental Research and Public Health, 16, 419. https://doi.org/10.3390/ijerph16030419

[35] Weintraub, W.S., Daniels, S.R., Burke, L.E., Franklin, B.A., Goff, D.C., Hayman, L.L., Lloyd-Jones, D. and Pandey, D.K. (2011) Value of Primordial and Primary Prevention for Cardiovascular Disease. Circulation, 124, 967-990.

https://doi.org/10.1161/CIR.0b013e3182285a81 